\title{
El principio de responsabilidad: Ensayo de una axiología para la tecnociencia
}

\author{
JAVIER ECHEVERRÍA \\ Instituto de Filosofía, CSIC
}

\begin{abstract}
RESUMEN. Se critica la concepción de Jonas del principio de responsabilidad, dado que las tecnociencias contemporáneas están cambiando las sociedades, y no únicamente la naturaleza biofísica. Se consideran brevemente las nuevas tecnologías de la información y las comunicaciones (TIC) como un buen ejemplo de tecnociencia. El principio de Jonas se toma como principio axiológico cuya formulación imperativa es problemática. Por medio de la distinción entre diferentes subsistemas de valores relevantes para las tecnociencias, concluimos que hay diferentes nociones de responsabilidad, relacionadas con esa pluralidad de tipos de valores.
\end{abstract}

\section{Introducción}

Parafraseando el título de la célebre obra de Hans Jonas ', en este artículo analizaremos cómo puede plantearse el problema de la responsabilidad en la ciencia y la tecnología contemporáneas. Para ello partiremos de un comentario crítico a los planteamientos de Jonas, quien sólo contempla uno de los aspectos del problema. Su formulación del principio de responsabilidad es insuficiente, porque la tecnociencia actual plantea problemas mucho más amplios que los considerados por dicho autor. La responsabilidad ha de ser considerada como una cuestión axiológica, no sólo como un principio ético. En general, mantendremos que lo importante es anali-
ABSTRACT. Jonas' conception of the principle of responsability is critizised, because the contemporary technosciences are changing societies, not only the biophysical nature. As a good example of technoscience, the new technologies of information and communication (TIC) are briefly considered. The jonasian principle is viewed as an axiological principle, whose imperative formulation is problematical. By distinguishing different subsystems of outstanding values for the technosciences, we conclude that there are different notions of responsability, related to these plurality of types of values.

zar el impacto de las tecnologías sobre la naturaleza, las sociedades y las personas: Jonas sólo se limita al primer punto.

Tras esos comentarios críticos, retomaremos los problemas planteados por el principio de responsabilidad desde la perspectiva de la axiología de la ciencia. Para ello haremos algunas breves consideraciones sobre el modo en que algunos filósofos de la ciencia y la tecnología (Popper, Mitcham) se plantean la cuestión de la responsabilidad de los científicos y los tecnólogos. Por nuestra parte, tras esbozar una teoría de las acciones científico-tecnológicas, mostraremos que hay varios sistemas de valores que guían la actividad tecnocientífica y permiten evaluarla. El principio de responsabilidad puede ser formula- 
do en referencia a cada uno de los subsistemas de valores, no sólo en relación a los valores éticos. Como conclusión, surge un nuevo marco conceptual para abordar la responsabilidad en la tecnociencia contemporánea.

\section{El principio de responsabilidad, según Jonas}

Resumamos las tesis iniciales de Hans Jonas en su libro El principio de responsabilidad, antes de pasar a su comentario crítico. Jonas considera que la tecnología «se ha convertido en una amenazas ${ }^{2}$, porque ha tenido «un éxito desmesurado» en su empresa de «sometimiento de la naturaleza» ${ }^{3}$. La naturaleza sometida a la intervención técnica del hombre se ha mostrado «vulnerable» ${ }^{4}$ y por ello la conservación de la biosfera, entendida como «un bien encomendado a nuestra tutela» ${ }^{5}$, se ha convertido en un problema moral, para cuyo tratamiento no valen las éticas clásicas. Éstas asumían tres premisas:

1. La condición humana, resultante de la naturaleza del hombre y de las cosas, permanece en lo fundamental fija de una vez para siempre.

2. Sobre esa base es posible determinar con claridad y sin dificultades el bien humano.

3. El alcance de la acción humana y, por ende, de la responsabilidad humana está estrictamente delimitado ${ }^{6}$.

Jonas argumenta que esas tres premisas ya no son válidas, punto en el que coincidimos plenamente con él. También tiene razón al afirmar que «dado que la ética tiene que ver con las acciones, seguidamente habremos de afirmar que la modificada naturaleza de las acciones humanas exige un cambio también en la ética» ${ }^{7}$. Cierto, pero no basta. Por supuesto que la ética tiene que ver con las acciones humanas, pero no sólo la ética: también la política, la economía o, por poner un ejemplo radical, las artes militares. Estas últimas generan acciones humanas, $\mathrm{e}$ incluso demasiado humanas, mas difícilmente podemos afirmar que están regidas por la ética. Al modificarse el alcance espacial y temporal de las acciones humanas no sólo cambian las premisas de la ética. Otros muchos saberes humanos han de ser repensados. Resumiremos nuestra propuesta diciendo que hay que replantearse los valores en general (políticos, sociales, económicos, militares, etc.), no sólo los valores morales.

En la medida en que las acciones humanas están guiadas por valores en general, no basta con replantearnos los problemas éticos. Esto hay que hacerlo, sin duda. Pero hay que dar un paso más: replantearse la axiología, que es mucho más amplia que la ética, al incluir valores económicos, sociales, políticos, jurídicos, etc., y también los valores tecnológicos y epistémicos. La actividad científico-tecnológica y, en general, las acciones humanas, no sólo están regidas por valores éticos, sino también por otros sistemas de valores, como los anteriormente mencionados ${ }^{8}$. $\mathrm{Al}$ considerar las acciones tecnológicas exclusivamente desde un punto de vista ético, Jonas restringe demasiado su análisis. Cuando Jonas afirma que hay que replantearse la orientación antropocéntrica de las éticas anteriores ${ }^{9}$, su propuesta es atinada, pero insuficiente. Desde los propios planteamientos de Jonas, lo que habría que replantear es el antropocentrismo de los valores, y no sólo de los valores éticos, sino también de otros tipos de valores, como los económicos, políticos, jurídicos y militares. De hecho, es lo que está ocurriendo hoy en día cuando se habla de desarrollo económico, pero sostenible, de limitar los niveles de contaminación, de prohibir las armas nucleares o bioquímicas, o de establecer moratorias para el desarrollo de las biotecnologías de clonación.

Tras estas consideraciones iniciales, Jonas afirma taxativamente que «la fronte- 
ra entre «Estado» (pólis) y «Naturaleza» ha quedado abolida. La ciudad del hombre, que antaño constituía un enclave dentro del mundo no humano, se extiende ahora sobre toda la naturaleza terrenal y usurpa su lugar. La diferencia entre lo artificial y lo natural ha desaparecido, lo natural ha sido devorado por la esfera de lo artificial» ${ }^{10}$. Por muy contundentes y seductoras que puedan resultar estas frases, lo cierto es que son exageradas. Los mares y el fondo del mar no han sido engullidos por el artificio humano, como tampoco las montañas, los desiertos o los casquetes polares. Tampoco ha desaparecido la muerte, que es algo muy natural. Es cierto que la pólis se ha expandido muchísimo, pero de ahí a decir que ya no hay physis media un abismo. Por otra parte, si ya no hubiera naturaleza y se hubiera convertido en artificio humano, ¿cómo afirmar el imperativo de conservar la naturaleza, como hace Jonas?

En la época premoderna, las ciudades humanas eran enclaves cerrados y protegidos, como afirma Jonas. Hoy en día las urbes se desparraman por extensos territorios y generan sus propias modalidades de naturaleza artificial (jardines, parques, alimentos transgénicos, especies tratadas genéticamente, etc.). Mas la physis no ha desaparecido de la superficie del planeta. En particular, no ha desaparecido la physis de los seres humanos, es decir, nuestros cuerpos. Por ello preferimos decir que el segundo entorno (pólis) se superpone al primero (physis), pero sin eliminarlo ${ }^{11}$. Jonas pecaba antes por defecto, al restringirse únicamente a la ética. Ahora peca por exceso, al afirmar que lo artificial ha devorado lo natural.

Mas vayamos al meollo de la cuestión: el nuevo imperativo categórico de Jonas. El imperativo kantiano era claramente antropocéntrico. Consecuentemente con lo dicho hasta ahora, Jonas propone un nuevo imperativo y proporciona hasta cuatro formulaciones del mismo:
Obra de tal modo que los efectos de tu acción sean compatibles con la permanencia de una vida humana en la Tierra; o, expresado negativamente: obra de tal modo que los efectos de tu acción no sean destructivos para la futura posibilidad de esa vida; o, simplemente: no pongas en peligro las condiciones de la continuidad indefinida de la humanidad en la Tierra; $\mathrm{o}$, formulado una vez más positivamente: incluye también en tu elección presente, como objeto también de tu querer, la futura integridad del hombre ${ }^{12}$.

Ya hemos expuesto en otro sitio nuestras críticas al imperativo kantiano ${ }^{13}$, por lo que dejamos claro nuestro escaso entusiasmo por el imperativismo moral, tan de moda entre los éticos. Hoy en día, parece que uno no puede hablar de ética sin formular su propio imperativo de cabecera ${ }^{14}$. En el caso de Jonas, nos centraremos en la cuarta formulación de su imperativo, que es la más innovadora y la que más influencia ha tenido.

Señalaremos cinco insuficiencias en el planteamiento de Jonas. La primera también le es atribuible a Kant: la ausencia de una teoría previa de la acción humana y, en el caso de Jonas, de la acción tecnológica. Cuando un filósofo utiliza el modo imperativo y dice «haz esto», o «haz lo otro», lo mínimo que hay que pedirle es que haya dejado previamente claro qué entiende por hacer.

En segundo lugar, Jonas tampoco propone ninguna definición o caracterización mínima de lo que puedan ser las tecnologías de las que habla. Continuamente afirma que las tecnologías modifican radicalmente las acciones humanas, pero no distingue entre técnica y tecnología, ni precisa a qué tecnologías se refiere cuando dice que la tecnología se ha convertido en una amenaza o que lo artificial ha devorado a lo natural. Su noción de tecnología es tan vaga e imprecisa que difícilmente puede ser considerada como un concepto filosófico.

En tercer lugar, ¿a quién se dirige el imperativo categórico jonasiano? ¿A cual- 
quier ser humano? ¿A los tecnólogos? ¿A los políticos? ¿A los que tienen el poder económico? ¿O, por qué no, a los militares? Al fin y al cabo, uno de los mayores riesgos actuales de destrucción de la biosfera proviene de la existencia de armas nucleares, y en concreto de la posibilidad de un invierno nuclear. Pero, ¿quién puede operar con esas armas? Únicamente algunos militares, o los presidentes de los gobiernos de algunas potencias nucleares, y ante todo el Presidente de los Estados Unidos de América. En la vida cotidiana de la inmensa mayoría de personas es difícil hallar alguna acción que pueda poner en peligro la conservación de la naturale$\mathrm{za}$, por lo que el pretendido imperativo ha de ser entendido más bien como un consejo, si no como una súplica dirigida a quienes de verdad tienen la capacidad de incidir gravemente sobre la naturaleza con sus acciones. Para un ciudadano normal y corriente la futura integridad del hombre se concreta en forma de paternidad responsable, lo cual nos parece muy bien, claro está. Aun así, entendemos que de ese principio de responsabilidad no surge una nueva ética, máxime si ni siquiera se alude al complejo problema del control de la natalidad, posibilitado precisamente por las nuevas tecnologías médicas y farmacológicas. ¿Ponen estas tecnologías en peligro la integridad futura del ser humano? ¿Es responsable utilizarlas o, a la inversa, es una irresponsabilidad con respecto a las generaciones futuras no usar las técnicas que permiten controlar la natalidad? Este tipo de problemas son importantes en bioética, pero Jonas no los afronta.

De lo anterior surge nuestra quinta crítica a Jonas: su noción de responsabilidad resulta excesivamente abstracta y de ella no se derivan normas para las acciones concretas. Según él, a la acción humana «se le ha agregado un objeto de orden totalmente nuevo, nada menos que la entera biosfera del planeta, de la que hemos de responder, ya que tenemos poder sobre ella» ${ }^{15}$. Es cierto que ello abre un nuevo problema. Pero de ahí a ser la base de una nueva ética hay una distancia muy grande. Por nuestra parte, optaremos por decir que a lo largo del siglo $\mathrm{Xx}$ ha emergido un nuevo subsistema de valores, los valores ecológicos, que no deben ser confundidos con los valores morales ${ }^{16}$, aunque se interrelacionen con ellos. La acción científica y tecnológica apenas ha tenido presente ese tipo de valores en la era moderna. Por tanto, es preciso abrir una reflexión axiológica (y en algunos casos ética) sobre los riesgos que se derivan de algunas acciones tecnocientíficas para la biosfera. Ahora bien, centrar la ética en esos nuevos problemas implica optar por lo que nosotros denominamos monismo axiológico. Para los monistas, los valores ecológicos o la ética ecológica devienen centrales y los demás sistemas de valores se subordinan a ellos. Al proceder así, la valoración de la tecnociencia resulta sesgada.

Conforme a nuestras tesis sobre el pluralismo axiológico, distinguimos al menos doce sistemas de valores relevantes para la acción científico-tecnológica. Uno de ellos está formado por los valores ecológicos. Pero, como veremos al final, la noción de responsabilidad puede ser planteada con respecto a varios de dichos sistemas de valores, no sólo en relación a los ecológicos. La ecología plantea importantes problemas de responsabilidad a los agentes tecnocientíficos. Pero no sólo la ecología. La tecnociencia produce profundos impactos sobre la naturaleza, pero también sobre la sociedad y las personas. La ética que propugna Jonas, además de abstracta, es reduccionista. Problemas éticos clásicos, por ejemplo, el repudio kantiano a la mentira, no pueden ser abordados desde el imperativo jonasiano. Por eso entendemos que sus planteamientos son insuficientes.

En resumen, las tesis iniciales de Jonas resultan un tanto decepcionantes si se piensa que el nuevo imperativo está dirigido a todos los seres humanos, no a unos 
pocos. Por otra parte, veremos más adelante que en otros pasajes de su libro Jonas defiende tesis muy dudosas, e incluso contradictorias con sus propios planteamientos, lo que hace desmerecer sus propuestas. Antes de pasar a ello haremos un breve interludio, comentando brevemente las tesis sobre la responsabilidad de los científicos e ingenieros de dos autores destacados en la filosofía de la ciencia y la tecnología del siglo xx: Popper y Mitcham.

\section{La responsabilidad de los científicos}

Karl Popper inició una conferencia pronunciada en 1968 diciendo que hablar de la responsabilidad moral de los científicos es «una forma eufemística de referirse al problema de la guerra nuclear y biológica» ${ }^{17}$. Sin embargo, el propio Popper afirmó a continuación que «el problema se ha hecho más general en los últimos tiempos debido a que últimamente la ciencia, y en verdad todo saber, ha tendido a ser potencialmente aplicable. Anteriormente, el científico puro o el estudioso puro sólo tenía una responsabilidad añadida a la de cualquier otra persona: esto es, la búsqueda de la verdad. Tenía que perseguir al máximo posible el crecimiento de su objeto» ... «Hoy, no sólo toda ciencia pura puede convertirse en ciencia aplica$\mathrm{da}$, sino también todo saber puro» ${ }^{18}$. Por ello Popper concluyó que «la responsabilidad moral de los científicos no se limita a su responsabilidad en relación con la guerra o el armamento» ${ }^{19}$.

El problema de la responsabilidad de los científicos y los tecnólogos es todavía más acuciante a principios del siglo XXI. Los estudios de Ciencia, Tecnología y Sociedad, que se iniciaron en los EEUU en los años setenta y que desde entonces se han desarrollado por doquier, se han ocupado ampliamente la cuestión de la responsabilidad de los científicos ${ }^{20}$. Por otra parte, cabe decir que, como Popper atisbaba, la propia ciencia ha cambiado, y no sólo porque todo saber puro puede aplicarse, sino porque cabe hablar de una nueva modalidad de ciencia, la tecnociencia (Big Science), que suscita continuamente problemas éticos y pone una y otra vez en cuestión la antigua asepsia moral de los científicos puros en tanto científicos. Dicho en otros términos: hoy no cabe mantener la separación entre la ciencia y los valores, como a lo largo del siglo $\mathrm{xx}$ hicieron los positivistas y buena parte de los científicos (por ejemplo, Poincaré, Russell, Einstein y otros muchos). La tecnociencia se ve confrontada con problemas éticos y axiológicos, y por ello la cuestión de la responsabilidad se ha convertido en una de las más importantes en los estudios CTS.

Hay razones de fondo para ello, como queda claro en la obra reciente de Carl Mitcham y Marcos García de la Huerta, La ética en la profesión de ingeniero. Ingeniería y ciudadanía ${ }^{21}$. García de la Huerta llama ética «a la teoría moral aplicada al ejercicio profesional de las ingenierías, pero, en general, a la responsabilidad en una cultura de expertos» ${ }^{22}$. El problema de la responsabilidad lo plantea en estos términos:

Hasta no hace mucho la cuestión de la responsabilidad del intelectual se circunscribía a la responsabilidad del escritor, del humanista, del cientista social, y el asunto quedaba definido única o preferentemente en términos de «compromiso» de un sujeto-autor. Era una responsabilidad limitada, egoica, cartesiana, procedente de un sujeto autónomo en ejercicio de una «razón soberana». El problema se revierte si la responsabilidad no viene tanto asociada al modo de entender la práctica de un saber o profesión, cuanto a los efectos que el ejercicio de ese saber o profesión provoca sobre el mundo natural y social. En este caso, el titular de la responsabilidad no es sólo el sujeto individual, sino el conjunto y cada uno de los miembros de 
un grupo o corporación. Lo cual no excluye la titularidad individual del sujeto moral, pero su importancia se desplaza y con ello se resignifica la «ética» como conducta pública ${ }^{23}$.

Retomaremos estas consideraciones desde nuestra propia perspectiva, centrada en la filosofía de la actividad científicotecnológica, más que en la filosofía de la ciencia entendida como epistemología. Resulta entonces que la ciencia y la tecnología no sólo son conocimiento, sino también acciones, y en concreto acciones que transforman el mundo físico y social. Para actuar se requieren agentes (actores, actuantes, hacedores), y por ello son precisas una teoría de la acción tecnocientífica y una teoría de los agentes científico-tecnológicos. Estos últimos son agentes individuales en primera instancia, pero, además, son también agentes institucionales, $\mathrm{o}$, si se quiere, sociales. Las acciones de investigación y aplicación de lo investigado en ciencia y tecnología no las llevan a cabo únicamente personas físicas, sino, por lo general, personas jurídicas: universidades, centros de investigación, empresas de I + D, agencias estatales, etc. Aunque la responsabilidad jurídica sea ante todo individual, también alcanza a las acciones colectivas. Tenemos así una ampliación del concepto de responsabilidad, y ello en el plano jurídico.

El problema se oscurece cuando hablamos de responsabilidad ética, porque lo que podríamos denominar individualismo ético, parafraseando el individualismo metodológico de los expertos en economía y en teoría de la decisión racional, impide hablar de una responsabilidad ética referida a colectivos, por ejemplo, a comunidades de científicos o tecnólogos. Sin embargo, la cuestión se clarifica cuando pasamos de la ética a la axiología y analizamos los valores que rigen las acciones tecnocientíficas, sean éstas individuales o colectivas. No es lo mismo la noción de responsabilidad ética que la de responsabi- lidad axiológica. Se trata de exponer esta última noción y de mostrar cómo el debate cambia por completo cuando investigamos la cuestión de la responsabilidad desde una perspectiva axiológica.

\section{Acciones tecnocientificas y responsabilidad axiológica}

Resumamos brevemente nuestras propuestas para una teoría de la acción tecnocientífica ${ }^{24}$. Decimos que una acción tecnocientífica $X$ siempre es evaluada en función de un sistema de valores $V$. Lo importante es analizar $X$ y $V$, precisando qué componentes tiene una acción y qué sistemas de valores son relevantes para valorar la acción y sus componentes.

Distinguimos en general doce componentes posibles de una acción tecnocientífica $X, X=<X_{1}, X_{2}, X_{3}, X_{4}, X_{5}, X_{6}, X_{7}, X_{8}$, $X_{9}, X_{10}, X_{11}, X_{12}>$, donde $X_{1}$ representa al agente (individual, colectivo), $X_{2}$ la acción, $X_{3}$ lo que se hace, $X_{4}$ aquello a lo que se le hace (objeto, persona, animal, etc.), $X_{5}$ los instrumentos con los que se hace, $X_{6}$ el lugar $o$ escenario donde se actúa, $X_{7}$ las condiciones en las que se lleva a cabo la acción (iniciales, de contorno), $X_{8}$ las intenciones o finalidades del agente, $X_{9}$ las reglas conforme a las cuales se actúa, $X_{10}$ los resultados de la acción, $X_{11}$ las consecuencias que se derivan de la acción y $X_{12}$ los riesgos que implica. Cuando $X_{4}$ es la biosfera en su conjunto, o una parte importante de ella, las propuestas de Jonas son aceptables, aun cuando siga sin quedar claro a quién se dirige su imperativo. Pero cuando un agricultor fumiga un campo para evitar plagas o cuando un médico opera a un cuerpo también se está actuando tecnocientíficamente sobre la physis. La cuestión de la responsabilidad no se plantea de la misma manera en un caso o en otro. Un agricultor puede arrasar un campo y poner en peligro el futuro suyo y de su familia. Un médico 
puede equivocarse al recetar un medicamento y ser responsable de la muerte de su paciente. Mas la responsabilidad de ambos, pese a existir, no cae bajo el imperativo jonasiano. Otro tanto cabe decir de las restantes componentes de las acciones tecnocientíficas, no sólo de la componente objetual $X_{4}$. Lo importante es tener en cuenta que hay diferentes tipos de responsabilidad y que, además, hay grados de responsabilidad. La gradualidad en la satisfacción o disatisfacción de los valores es una tesis axiológica básica, que nos lleva a un análisis muy distinto al de las éticas basadas en principios imperativos categóricos.

Las acciones tecnocientíficas siempre son valoradas, positiva o negativamente, conforme a grados mayores o menores de satisfacción de los valores. Además, es importante subrayar que no sólo se evalúan los resultados de las acciones (componente $X_{10}$ ), sino también las restantes componentes. En el caso de la investigación científico-tecnológica hay que distinguir entre los resultados de una acción, sus consecuencias ulteriores y los riesgos previsibles de dicha acción. Meterlo todo en un mismo saco no es aceptable filosóficamente, por frecuente que sea proceder así en la ética principialista, y mucho más en las éticas de inspiración monista. Por ejemplo, aunque en principio la responsabilidad de una acción recae siempre sobre el agente que la lleva a cabo, lo cierto es que en numerosas ocasiones los fallos pueden provenir de los instrumentos, en cuyo caso la responsabilidad recae sobre el fabricante de dichos instrumentos, no sobre el agente inmediato. $\mathrm{O}$, por poner un segundo ejemplo, las circunstancias en las que se lleva a cabo una acción (estado de necesidad, legítima defensa, imprudencia no consciente, etc.) también inciden sobre la responsabilidad de los agentes, como bien saben los jueces. Otro tanto vale para los juicios éticos. No es lo mismo matar plantas que animales o seres humanos. $\mathrm{La}$ valoración moral de la acción de matar cambia en función de los objetos que son aniquilados (y los tres citados son physis). Incluso los defensores de los derechos de los animales distinguen claramente entre unos tipos u otros de animales, así como entre las plagas y las especies en vías de extinción. La valoración de la muerte humana también cambia en función de la situación, por ejemplo en estado de guerra. En resumen, es preciso disponer de una teoría de la acción y analizar sus componentes si queremos valorar las acciones humanas, y más todavía si queremos suscitar la cuestión de la responsabilidad de dichas acciones. Un principio de responsabilidad que instituya una única pregunta a responder, prescindiendo de las otras muchas que hay que tener en cuenta a la hora de valorar, puede resultar atractivo por su simplicidad, pero sesga enteramente los procesos de valoración de las responsabilidades.

Por otra parte, es imprescindible tener presente que el problema de la responsabilidad no se limita a la ética, sino que involucra a la axiología, la cual, como ya dijimos, es mucho más amplia que la ética. Aludimos anteriormente a doce sistemas de valores relevantes a la hora de evaluar las acciones tecnocientíficas. Los enumeraremos por orden alfabético, precisamente para no reducir a priori el problema filosófico suscitado por la acción de valorar: valores básicos, ecológicos, económicos, epistémicos, estéticos, jurídicos, militares, morales, políticos, religiosos, sociales y tecnológicos. Cada acción tecnocientífica concreta puede ser valorada por lo general teniendo en cuenta únicamente algunos de estos sistemas de valores, pero la axiología de la tecnociencia en su conjunto ha de distinguir al menos esos doce sistemas, puesto que la enorme diversidad de acciones tecnocientíficas pone en juego esa gran variedad de cuestiones axiológicas. Por ello decimos que el sistema $V$ de valores de la tecnociencia está formado en 
general por doce subsistemas de valores, $V=<V_{1}, V_{2}, V_{3}, V_{4}, V_{5}, V_{6}, V_{7}, V_{8}, V_{9}, V_{10}$, $V_{11}, V_{12}>$. El acto de valorar una acción tecnocientífica consiste en aplicar el sistema $V$ a una acción $X$, obteniéndose como resultado la expresión $V(X)$, que puede ser representada mediante una matriz de evaluación, $v_{i j k}\left(X_{i}\right)$, donde $i$ designa las componentes de una acción, $j$ los subsistemas de valores y $k$ los diversos valores de cada subsistema $\left(V_{j}=\left(v_{j k} l\right)\right.$. En cada proceso de evaluación el sistema $V$ incluye unos determinados valores, no siempre los mismos. Sin embargo, las evaluaciones tecnocientíficas siempre conllevan una serie de valores compartidos. Entre ellos puede haber valores éticos, y si quiere también ecológicos. Mas no hay que olvidar los restantes tipos de valores y las diversas cuestiones de responsabilidad que suscitan. Entre los diversos sistemas y valores concretos unos tendrán más peso específico que otros en función de los agentes, objetos a evaluar, condiciones y objetivos de la evaluación, etc. Por ello representamos las acciones de evaluación mediante matrices ponderadas, $\left(p_{i j k} \cdot v_{i j k}\left(X_{i}\right)\right)$, existiendo en general unas cotas mínimas de satisfacción de los valores (y máximas de disatisfacción de los disvalores), $c_{i j k}\left(X_{i}\right)$ y $C_{i j k}\left(X_{i}\right)$, de modo que $c_{i j k}\left(X_{i}\right)<p_{i j k} . v_{i j k}\left(X_{i}\right)$ $<C_{i j k}\left(X_{i}\right)$. Diremos que, en general, los problemas de responsabilidad surgen cuando esas desigualdades no se cumplen, sobre todo en relación con las componentes $X_{10}, X_{11}, X_{12}$, es decir, cuando valoramos resultados, consecuencias y riesgos, una vez realizada la acción $X$. Lo importante es que la cuestión de la responsabilidad surge para los diversos valores $v_{i j k}$ que son relevantes para valorar estas tres últimas componentes, no sólo para los valores éticos y ecológicos.

¿Cómo pueden aplicarse estas propuestas, tan sucintamente recordadas, al problema de la responsabilidad tecnocientífica? Mencionaremos únicamente los aspectos más relevantes, con el fin de mostrar las profundas diferencias entre un enfoque axiológico y uno puramente ético como el de Jonas.

Lo primero que hay que señalar es que, al distinguir varios sistemas de valores relevantes para la actividad tecnocientífica, la noción de responsabilidad adquiere diversas facetas. De acuerdo con nuestra propuesta hay que distinguir varios tipos de responsabilidad: moral, ecológica, jurídica, política, social, militar, etc., pero también una responsabilidad epistémica y otra técnica, o tecnológica. Estas dos últimas son las más novedosas, por lo que insistiremos más en dichos aspectos de las acciones científico-tecnológicas.

La idea subyacente es muy sencilla. Antes de llevar a cabo sus acciones (de investigación, de aplicación, de enseñan$\mathrm{za}$, etc.) un científico ha de ser epistémicamente responsable, es decir, ha de haberse formado como científico, ha de contrastar sus conocimientos a base de informarse, ponerse al día, preguntar a expertos con mayor conocimiento y experiencia, etc. En particular, ha de preocuparse por los modos en que otros científicos acostumbran resolver los dilemas éticos, los problemas ecológicos, etc., que se derivan de las acciones que ejecutan. Un modo típico de ser responsable a la hora de hacer experimentos, observaciones, mediciones, etc., consiste en ponerse en el lugar del otro, es decir: llevar a cabo dichas acciones consigo mismo, o en su entorno inmediato, cuando menos imaginando dichas acciones posibles ejecutadas sobre sí mismo. En general, ser un profesional científico implica superar habitualmente las cotas mínimas $c_{i j k}$ de los diversos valores epistémicos relevantes y estar por debajo de las cotas máximas para los disvalores epistémicos (imprecisión, incoherencia, ausencia de rigor, etc.). Cuando las acciones científicas se convierten en hábitos, entonces la satisfacción de los valores epistémicos se da por sobreentendida. La responsa- 
bilidad surge en aquellas acciones en las que, por las razones que sea, el grado de satisfacción cae por debajo de los umbrales mínimos exigibles a un científico.

Ser responsable técnicamente implica hacer bien las cosas, es decir, conocer el oficio propio y llevar a cabo las acciones con cuidado y con atención, con el fin de evitar errores técnicos en la manipulación de artefactos, etc. Implica también voluntad de aprender de quienes son técnicamente mejores en la práctica científica. Un ejemplo obvio de responsabilidad técnica sería el de un médico, pero esa noción de responsabilidad vale también para otras prácticas científicas. Un piloto de avión, un arquitecto, un constructor de presas o un diseñador de ordenadores también llevan a cabo acciones tecnocientíficas. Independientemente de la valoración económica, ecológica, social, etc., de dichas acciones, siempre se puede hacer además una valoración técnica. Esos valores técnicos (eficiencia, utilidad, competencia, etc.) también se incorporan a los hábitos de los agentes. Por ello los ingenieros y tecnólogos insisten tanto en su profesionalidad: porque ello implica la asunción duradera de determinados valores que se cumplen suficientemente.

Otro tanto cabría decir de los restantes tipos de valores, a los cuales no vamos a referirnos, para no alargarnos. Lo importante es que, desde una perspectiva axiológica, los problemas de responsabilidad surgen por diversas razones: por ejemplo, por falta de precisión, o de competencia, o de eficiencia. En tales casos a los profesionales les son exigibles responsabilidades. Pero dichas responsabilidades son epistémicas o técnicas, no morales. Normalmente son las propias comunidades tecnocientíficas las que toman a su cargo esa noción de responsabilidad, sin perjuicio de que, además, pueda haber responsabilidades morales, jurídicas, políticas, sociales, ecológicas, militares, etc.
Al distinguir diversos tipos de responsabilidad no negamos la responsabilidad moral de los científicos e ingenieros. Aceptamos incluso que en algunas acciones tecnocientíficas la responsabilidad moral es la más importante, incluso mayor que la responsabilidad militar, política o jurídica. Sin embargo, hay otras muchas acciones tecnocientíficas en las que, aun involucrando aspectos morales, estos últimos no son los más importantes a la hora de valorar la responsabilidad del científico o del ingeniero. El pluralismo axiológico exige analizar siempre el peso relativo que tiene cada subsistema de valores a la hora de evaluar las acciones, sus resultados, sus consecuencias y sus riesgos. Hay acciones científico-educativas que pueden tener consecuencias éticas nefastas, por ejemplo, al promover valores racistas, xenófobos, discriminatorios, inmorales, etc. Pero no hay que olvidar que, por ejemplo, si una comunidad científica se empeña en mantener contenidos docentes periclitados, acaso por conservar influencia y poder académico, también incurre en responsabilidades, aunque éstas sean ante todo epistémicas y sociales. Es importante tener presente que las acciones científicotecnológicas no sólo son de investigación, innovación y aplicación del conocimiento, sino que también versan sobre la transmisión del conocimiento. Las responsabilidades epistémicas también aparecen en el contexto de educación, no sólo en el de descubrimiento e innovación.

Pasemos a otros sistemas de valores, aunque sea muy brevemente. La responsabilidad por acciones de guerra tiene sus propios criterios de valoración, que han de ser analizados y distinguidos de otros tipos de responsabilidades (políticas, jurídicas, etc.). Los crímenes de guerra son una modalidad específica de criminalidad, que han de ser juzgados en función de sistemas específicos de valores (obediencia debida, ensañamiento, etc.). También cabe hablar de responsabilidad desde un punto 
de vista estrictamente económico, como en cualquier empresa se sabe muy bien. En resumen, la perspectiva axiológica que propugnamos distingue diversas acepciones del «principio de responsabilidad», tantas como subsistemas de valores relevantes distingamos. Esto nos permite analizar y clarificar el concepto de responsabilidad, en lugar de usarlo como una noción ambigua y abstracta. Por supuesto, cabe hablar de responsabilidad moral y ecológica. Pero la responsabilidad por las acciones tecnocientíficas no se agota en la ética y en la ecología, como parece inferirse de las tesis de Jonas.

\section{Algunas incoherencias en los planteamientos de Jonas}

Una vez expuestas las profundas diferencias conceptuales entre un planteamiento axiológico de la responsabilidad y uno ético-ecológico (a lo Jonas), pasemos, sin embargo, a analizar más a fondo algunas tesis de Jonas. Incluso restringiéndonos a su propia perspectiva, quedan divergencias que conviene resaltar.

Ya dijimos que Jonas no precisa en ningún momento su noción de tecnología. Nosotros partiremos de la definición propuesta por Quintanilla, para quien la técnica es «un sistema de acciones humanas intencionalmente orientado a la transformación de objetos concretos para conseguir de forma eficiente un resultado valioso» ${ }^{25}$. A continuación distinguió la técnica y la tecnología en base a dos criterios: esta última siempre está basada en conocimiento científico, lo cual no tiene por qué ocurrir con la técnica $\mathrm{y}$, además, está vinculada a la producción industrial. Por nuestra parte, ampliaremos las propuestas de Quintanilla, diciendo que la tecnociencia es una modalidad de ciencia en la que la actividad científica tiene como requisito necesario a la tecnología. Dicho de otra manera: así como la tecnología se distingue de la técnica por estar basada en conocimiento científico, así también la tecnociencia se distingue de la ciencia por estar basada en conocimiento tecnológico, sin perjuicio de que la ciencia siempre ha tenido una componente técnica e instrumental indudable ${ }^{26}$.

Este tipo de caracterizaciones de la técnica, la tecnología y la tecnociencia pueden ser objetadas, pero, equivocadas o no, poseen al menos un cierto grado de precisión conceptual. No es lo mismo concebir la tecnología como un sistema de artefactos o como la artificialización del mundo, como hace Jonas, que pensarla como un sistema de acciones humanas y/o sociales. En esta segunda concepción, quienes dominan y hacen vulnerable a la naturaleza no son las tecnologías, sino los seres humanos que llevan a cabo dichas acciones tecnológicas con el fin de dominarla y explotarla. No es lo mismo ser tecnófobo en relación a los aparatos, como Jonas se muestra a veces, que tratar de identificar los grupos sociales que son responsables de dichas acciones tecnológicas, por ser quienes las promueven y ejecutan. Las acciones tecnológicas de Jonas parecen carecer de agentes, como si toda tecnología fuera robótica y automática. Se diría que nos dominan las máquinas, no los seres humanos que las diseñan y construyen con el fin de dominarnos, o de dominar la naturaleza.

En este sentido, llama la atención que Jonas analice la era moderna como un despliegue acumulativo e imparable del dominio técnico del mundo mientras guarda un silencio significativo sobre una componente de la modernidad tan relevante como el capitalismo industrial ${ }^{27}$. Al desligar la promoción de la tecnología de la expansión del capitalismo por todo el planeta Jonas prescinde de los valores económicos inherentes a la tecnología, o cuando menos no los analiza. Dicho de otra manera: la limitación de los beneficios industriales hubiera sido una buena 
vía para paliar los efectos destructivos de la explotación tecnoindustrial de los recursos naturales, incluido, por cierto, el cuerpo humano. Al analizar las acciones humanas, y más concretamente las científicas y las tecnológicas, es preciso discernir los agentes que están detrás de ellas, así como sus intereses y valores.

Por lo general, Jonas guarda silencio sobre las tecnologías militares, y más concretamente sobre la energía nuclear y las bombas atómicas, que han sido las primeras en mostrar la vulnerabilidad de la naturaleza que él denuncia ${ }^{28}$. Pero las raras veces que rompe ese silencio, su honestidad intelectual queda en entredicho: «ni siquiera el eventual uso de las armas nucleares con su evidente fin - a saber, el aniquilamiento - delata que el fin de su acumulación es que no sean utilizadas» ${ }^{29}$, afirma en un momento dado, asumiendo valores militares, aun sin mencionarlos. $\mathrm{O}$ también: «la fusión nuclear, si algún día nos es regalada, podría solucionar para siempre el problema de la energía» ${ }^{30}$, y más adelante: «la mayor revolución científico-práctica en la historia de la física -el descubrimiento de los secretos del átomo- contiene en su potencial tanto la salvación de la humanidad como su aniquilamiento» 31

Resulta paradójico que el formulador del nuevo imperativo categórico y defensor de una nueva ética mantenga este tipo de posturas las pocas veces que analiza acciones tecnocientíficas concretas, en lugar de refugiarse en el concepto abstracto de tecnología. Cifrar la salvación de la humanidad en el descubrimiento de la energía nuclear, y que ello se haga desde planteamientos éticos, resulta simplemente ridículo. Del imperativo categórico jonasiano más bien se derivarían máximas del tipo: «no acumules armas nucleares» o «no produzcas energía nuclear mientras no hayas resuelto el problema de los residuos nucleares» 0 «busca formas alternativas de energía, por ejemplo, energías renova- bles». Mucho más si tenemos en cuenta que, en otro apartado de su libro, Jonas propugna "el precepto de que hay que dar mayor crédito a las profecias catastrofistas que a las optimistas» ${ }^{32}$. En relación a las armas nucleares, la postura optimista se resume en lo que el propio Jonas dice: conviene acumular armas nucleares con el fin de no utilizarlas, es decir, como disuasión. La catastrofista afirmaría, en cambio, que si alguien acumula esas armas es para utilizarlas masivamente. Y la postura intermedia, a mi entender, más ajustada a la realidad (piénsese en las bombas de plutonio), afirmaría que dichas armas no se acumulan para utilizarlas contra la naturaleza, sino contra los seres humanos que defienden valores e intereses opuestos a los de los agentes que acumulan dichas armas. En cualquier caso, este ejemplo muestra que la aparente preocupación de Jonas por el futuro de la biosfera no se compadece con sus tesis relativas a las armas y la energía nuclear. Buena parte de las acciones tecnológicas más preocupantes del siglo $x x$ tienen como objetivo transformar al hombre y a la sociedad, no a la naturaleza. Cabe incluso decir que ésta es una de las principales diferencias entre la tecnociencia y la tecnología, aunque aquí no vayamos a entrar en este punto ${ }^{33}$. Por ello pensamos que las propuestas de Jonas contribuyen más bien a desenfocar el análisis axiológico de la tecnociencia, al orientar el debate hacia lugares donde no se plantean los problemas principales.

Sin embargo, es preciso recordar que hay un apartado (I.5) en el que Jonas sí se ocupa del hombre como objeto de la técnica. Ahí empieza de forma prometedora:

Mas no hemos mencionado la clase potencialmente más ominosa de tales obras (técnicas). Únicamente hemos examinado la aplicación de la techné al ámbito no humano. Sin embargo, el propio hombre se ve incluido entre los objetos de la técnica. El homo faber vuelve su arte sobre sí mismo y se dispone a rehacer innovadoramente al inventor y fabricante de 
todo lo demás. Esta culminación de su poder, que puede muy bien significar el sometimiento del hombre, esta última intervención del arte en la naturaleza, es un desafío a los máximos esfuerzos del pensamiento ético, que nunca antes tuvo que vérselas con alternativas elegibles frente a lo que se consideraba datos definitivos de la condición humana ${ }^{34}$.

Pese a este estimulante comienzo, Jonas sólo habla luego de la medicina y de la prolongación de la vida, a la que atribuye grandes riesgos: «de este modo tendríamos un mundo de viejos en el que no habría juventud» ${ }^{35}$. También menciona un segundo ejemplo, el de la manipulación genética, que «desborda los conceptos de toda ética ulterior» ${ }^{36}$. Jonas jamás se refiere a las tecnologías que cambian la sociedad. Y los dos ejemplos que pone no son tecnologías orientadas al dominio del hombre, sino en todo caso al de la physis humana. Que la naturaleza del hombre sea la de un ser social y que dicha naturaleza también pueda ser modificada tecnológicamente no parece entrar en el campo de sus preocupaciones filosóficas. Por eso siempre contrapone techné y physis (biophysis), nunca techné y pólis. Para estudiar el problema de la responsabilidad en el caso de las tecnologías de la información y la comunicación la segunda opción es la más importante, por lo que las propuestas de Jonas no tienen especial interés al respecto.

Por último, hay que criticar su insistencia en que la cuestión de la responsabilidad es ética, no política, y ello a pesar de que al principio de su libro reconoce que el sujeto de la acción tecnológica, al que suele denominar «actor» o «hacedor», es «el actor colectivo y el acto colectivo, no el actor individual o el acto individual» ${ }^{37}$. Siendo así, ¿no habría que admitir también un principio de responsabilidad política, concretamente en el caso de las políticas tecnológicas?

Habría otras muchas críticas a hacer a Jonas, pero lo dicho hasta ahora puede valer para mostrar que en sus propuestas hay varias lagunas e insuficiencias. A nuestro entender, la perspectiva axiológica que hemos propuesto permite una valoración mucho más afinada y equilibrada de la tecnociencia contemporánea, sobre todo porque ésta es entendida como una acción humana que tiene agentes concretos. Ellos son los sujetos de responsabilidad, no la tecnología en abstracto.
$1 \mathrm{H}$. Jonas, El principio de responsabilidad. Ensayo de una ética para la civilización tecnológica, Barcelona, Herder, 1995.

${ }^{2}$ H. Jonas, op. cit., p. 15.

${ }^{3}$ lbid.

${ }^{4}$ lbid., p. 32.

${ }^{5}$ lbid., p. 35

6 Ibid., p. 23

7 lbid.

${ }^{8}$ La axiología de la tecnociencia que propugnamos parte de la tesis del pluralismo axiológico (vid. J. Echeverría, Filosofía de la Ciencia, Madrid, Akal, 1995, cap. 2, y distingue diversos subsistemas de valores relevantes para la ciencia y la tecnología. Vid. J. Echeverría, Ciencia y Valores (Barcelona, Destino, 2002) para una exposición más amplia sobre dicha axiología de la ciencia, así como Los Valores de la Tecnociencia, por aparecer en México, FCE.

9 H. Jonas, op. cit., pp. 34-35.

1 lbid, p. 37.

"1 Para un desarrollo más amplio de estas ideas, ver J. Echeverría, Los Señores del Aire: Telépolis y el Tercer Entorno, Barcelona, Destino, 1999.

12 Ibid., p. 40.

13 Vid. J. Echeverría, «¿Qué puedo hacer, y no debo?», en Roberto R. Aramayo y J. Francisco Álvarez (eds.), A ciencia incierta, México, FCE, 2001.

${ }_{14}$ En el mencionado artículo también formulamos nuestro propio «imperativo» axiológico, que tiene la peculiaridad de no ser un imperativo, ni mucho menos categórico.

15 Jonas, op. cit., p. 33. 
16 Un valor importante en ecología es la biodiversidad, que difícilmente puede ser considerado como un valor ético. Los autores que escriben sobre kética ambiental» suelen hablar de «valores ontológicos» al aludir a estas cuestiones.

$17 \mathrm{~K}$. Popper, El mito del marco común, Barcelona, Paidós, 1997, p. 123.

18 Ibid.

19 Popper, op. cit., p. 128.

${ }^{20}$ Un buen resumen de cómo se plantea el problema de la responsabilidad en los estudios CTS puede hallarse en la obra de José Antonio López Cerezo y José Luis Luján, Ciencia y Política del riesgo, Barcelona, Paidós, 2000.

${ }^{21}$ Chile, Universidad de Chile, 2001.

${ }^{22}$ Op. cit., p. 12.

${ }^{23}$ Ibid., pp. 12-13.

24 Expuesta en J. Echeverría 2002, op. cit., cap. 2.

${ }_{25}$ M. A. Quintanilla, Tecnología. Un enfoque filosófico, Madrid, Fundesco, 1989, p. 34
${ }^{26}$ Para una caracterización más amplia de la tec nociencia, vid. Echeverría 2002, obra por aparecer en esta editorial.

27 Al respecto sólo hay una breve alusión al capitalismo como realización del programa baconiano (Jonas, op. cit., p. 233)

28 Piénsese en el invierno nuclear, que sólo podría producirse como consecuencia de acciones militares de bombardeo nuclear masivo. Analizar quién posee los medios de acción tecnológica siempre es aconsejable a la hora de atribuir responsabilidades por las acciones.

29 Jonas, op. cit., p. 108.

30 Ibid., p. 309.

31 Ibid., p. 311.

${ }^{32}$ Ibid., p. 71.

$33 \mathrm{Vid}$. al respecto la obra ya mencionada, Los valores de la tecnociencia.

34 Jonas, op. cit., p. 49.

35 lbid., p. 51

36 Ibid., p. 54

${ }^{37}$ Ibid., p. 37. 